\title{
Efficacy of fenbendazole against gastrointesti- nal nematodes in white-tailed deer
}

\author{
STEPHEN R. SCHULTZ, ROBERT X. BARRY, WILL A. FORBES, AND MARK K. \\ JOHNSON
}

\begin{abstract}
Authors are assistant professor, School of Forestry, Wildlife, and Fisheries, Louisiana State University Agricultural Center, Baton Rouge 70803; biologist, U.S. Army Corps of Engineers, CELMK-PD-Q, Vicksburg District Office, 1-20 Frontage Road, Vicksburg, Miss. 39180; graduate research assistant, School of Forestry, Wildlife, and Fisheries, Louisiana State University Agricultural Center, Baton Rouge; and professor, School of Forestry, Wildlife, and Fisheries, Louisiana State University Agricultural Center, Baton Rouge. At the time of the research Robert X. Barry was a graduate research assistant, School of Forestry, Wildlife, and Fisheries, Louisiana State University. Agricultural Center, Baton Rouge.
\end{abstract}

\begin{abstract}
We provided fenbendazole to captive $(\mathbf{N}=77)$ and free-ranging (3 study areas) white-tailed deer (Odocoileus virginianus) in Louisiana to determine effects on gastrointestinal nematode burdens. Fenbendazole reduced gastrointestinal nematode burdens of captive and free-ranging white-tailed deer. Mean eggs per gram of feces from captive deer decreased $P<0.01$ and $P<0.01$, respectively) $89 \%$ and $84 \%$ after provision of fenbendazole in doses approximating 0.47 and $0.62 \mathrm{~g} /$ deer, respectively. Doses approximating $0.42-0.46 \mathrm{~g} /$ deer did not affect $(P=0.61)$ eggs per gram of feces collected from free-ranging deer. Mean eggs per gram of feces collected from free-ranging deer was affected by fenbendazole treatment $(P=0.04)$ and decreased an average of $86 \%(\mathrm{SE}=1.9)$ on the 3 study areas after provision of fenbendazole in doses approximating 1.67-1.82 g/deer. Eggs per gram of feces collected from the distal colon and abomasal parasite counts from abomasa of freeranging deer harvested on the study areas were associated positively $(r=0.706, P<0.001)$, were affected by fenbendazole treatment $(P<0.01$ and $P<0.01$, respectively), and decreased 66\% (SE $=$ $5.1)$ and $52 \%(\mathrm{SE}=7.4)$, respectively, after provision of fenbenda-

Funding was provided by Hoeschst-Roussell Agri-Vet Company, Inc., Somerville, N.J. Additional materials were provided by Urbana Laboratories, St. Joseph, Mo. Authors wish to thank T. Jones and G. Berger for use of their lands and V. Herbert and N. Bradley for assistance with data collections. This manuscript was approved for publication by the Director, Louisiana Agricultural Experiment Station as Manuscript 91-22-5248.

Manuscript accepted 24 Oct. 1992.
\end{abstract}

zole in doses approximating 1.67-1.82 $\mathrm{g} /$ deer. A reduction in the crosstransmission of gastrointestinal parasites common to deer and livestock might be possible through fenbendazole treatment of deer.

Key Words: anthelmintic, disease, Louisiana, Odocoileus virginianus, parasites

Domestic livestock and white-tailed deer (Odocoileus virginianus) share common range in much of the United States, increasing the potential for crossinfection of endoparasites among these ruminants (Beaudion et al. 1970). Prestwood and Pursglove (1981) reported that 32 species of gastrointestinal nematodes have been recorded in white-tailed deer, several of which also infect livestock (Anderson 1962, Prestwood et al. 1973, Prestwood et al. 1975, Prestwood et al. 1976, Davidson et al. 1980, McGhee et al. 1981, Conti and Howerth 1987). Livestock operations often utilize some control program against gastrointestinal parasites and fenbendazole has been demonstrated to be an effective drug for treatment of gastrointestinal parasites in domestic ruminants (Fraser 1986). Free-ranging deer could potentially serve as a reservoir for gastrointestinal nematodes (Dunn 1968, McGhee et al. 1981) and lead to reinfection of treated livestock.

Most species of gastrointestinal nematodes are nonpathogenic or mildly pathogenic in free-ranging white-tailed deer under normal circumstances (Prestwood and Pursglove 1981). However, heavy infection combined with malnutrition led to mortality and 
morbidity of white-tailed deer on the Atlantic and Gulf coastal plains (Davidson et al. 1980) and other detrimental cases have been reported (Prestwood and Kellogg 1971, Forrester et al. 1974). Fawn and yearling deer are particularly susceptible to pathogenic gastrointestinal nematode infections (Prestwood and Kellogg 1971, Forrester et al. 1974, Conti and Howerth 1987).

Deer population reduction has been suggested as a management tool to minimize the risk of parasite-related disease because parasite burdens have been shown to be related to deer densities in some regions of North America (Herman 1945, Eve and Kellogg 1977, Davidson et al. 1982). However, many free-ranging deer populations are maintained at high densities through design or default. Treatment with anthelmintics may be a reasonable strategy to increase productivity of farmed deer or to reduce the potential for parasite-related disease problems in free-ranging deer and potentially reduce reinfection of livestock utilizing the same range (Qureshi et al. 1989, 1990).

Administration of anthelmintics to populations of wild animals is in its infancy (Foreyt and Samuel 1979). Garris et al. (1991) used ivermectin-treated corn (Zea mays L.) to control the domestic rabbit ear mite (Psoroptes cuniculi) in captive white-tailed deer; and Qureshi et al. $(1989,1990)$ used tricalbendazole and albendazole, respectively, to control Fascioloides magna in white-tailed deer. The majority of investigations regarding the use of anthelmintics in nondomestic animals have dealt primarily with European species, zoo animals, and farmed deer; and treatment with 5-50 $\mathrm{mg}$ fenbendazole/ $\mathrm{kg}$ body mass has been effective in reducing gastrointestinal nematode burdens in these nondomestic species (Bockeler and Lindau 1978, Dinnes and Knapman 1980, Duwel et al. 1979, Janssen 1985, Kutzer 1981, Wiegand 1981). We could find no reports of the use of this anthelmintic for treatment against gastrointestinal nematodes in white-tailed deer. Therefore, our study was designed to determine if gastrointestinal nematode burdens in captive and free-ranging white-tailed deer could be affected through fenbendazole treatment.

\section{Materials and Methods}

\section{Study Areas}

Captive deer were housed in a 6.5-ha paddock of native grasses and mature pecans (Carya illinoensis K. Koch) on Idlewild Experiment Station, East Feliciana Parish, La. Avondale Hunting Camp (Avondale, $351 \mathrm{ha}$ ) and portions of Blairstown Plantation (Blairstown, 980 ha) and Shades Plantation (Shades, 240 ha) were used to examine efficacy of fenbendazole for treatment of gastrointestinal nematodes in free-ranging deer. All areas were located in EastFeliciana Parish, La., and vegetation was typical of mixed pinehardwood upland forests in the southeastern United States (Delany 1985, Barry 1991).

\section{Captive Deer}

Two trials were conducted using 77 captive, adult $(\geq 2$ years-ofage) white-tailed deer. We lightly coated $136 \mathrm{~kg}$ pelleted feed with a commercial inoculum sticker (VW-4; Urbana Laboratories, St. Joseph, Mo.) to administer $20 \%$ fenbendazole premix (HoechstRoussel Agri-Vet Co., Somerville, N.J.) for both trials. We administered $180 \mathrm{~g}$ premix ( $36 \mathrm{~g}$ fenbendazole; $x=0.47 \mathrm{~g} /$ deer ) and $240 \mathrm{~g}$ premix ( $48 \mathrm{~g}$ fenbendazole; $x=0.62 \mathrm{~g} /$ deer) on 16 May and 9 August 1990, respectively.

We collected 30 freshly deposited fecal samples immediately prior to each treatment and approximately 2 weeks following each treatment (30 May and 21 August 1990). We processed fecal samples using a double-centrifugation, sugar-floatation technique (Samuel and Trainer 1969) to recover gastrointestinal nematode eggs. The number of gastrointestinal nematode eggs per gram of feces in each sample was used to index gastrointestinal nematode abundance. Fecal egg counts have been used as a nondestructive method to evaluate control measures against gastrointestinal nematode parasites in zoo animals and farmed deer (Bockeler and Lindau 1978, Dinnes and Knapman 1980, Mason and Gladden 1983, Anderson and Wilson 1984, Wilson 1984, English 1985, Janssen 1985, Watson and Charleston 1985, Boyce et al. 1991).

\section{Free-Ranging Deer}

We conducted 3 Haynes' strip censuses (Hayne 1949) at each area and estimated approximately 1 deer $/ 4.4$ ha ( 79 deer) at Avondale, 1 deer $/ 6.0$ ha at Blairstown ( 163 deer), and 1 deer $/ 2.8$ ha ( 86 deer) at Shades. We prebaited deer to covered bait stations at each study area (6 at Avondale, 12 at Blairstown, and 6 at Shades) beginning in February 1990 and provided whole, shelled corn ad libitum at bait stations throughout the study.

We conducted 3 trials for free-ranging deer and used a light coating of inoculum sticker, as in the captive deer trials, to fix $20 \%$ fenbendazole premix to corn. We mixed $30 \mathrm{~g}$ of $20 \%$ fenbendazole premix with $23 \mathrm{~kg}$ coated corn at each bait station in May 1990 for Trail 1. The amount of corn supplied was based on consumption rates during prebaiting such that fenbendazole would be consumed within 3-5 days. We provided $180 \mathrm{~g}$ ( $36 \mathrm{~g}$ fenbendazole), $360 \mathrm{~g}(72 \mathrm{~g}$ fenbendazole), and $180 \mathrm{~g} \mathrm{(} 36 \mathrm{~g}$ fenbendazole) premix at Avondale, Blairstown, and Shades, respectively.

We mixed $60 \mathrm{~g}$ of $20 \%$ fenbendazole premix with $23 \mathrm{~kg}$ coated corn at each bait station in July and November 1990 for Trials 2 and 3 , respectively. We provided an additional $60 \mathrm{~g}$ premix mixed with $23 \mathrm{~kg}$ coatcd corn at each bait station after all medicated corn originally provided had been consumed. For Trials 2 and 3 we provided $720 \mathrm{~g}$ ( $144 \mathrm{~g}$ fenbendazole), $1,440 \mathrm{~g}$ ( $288 \mathrm{~g}$ fenbendazole), and $720 \mathrm{~g}$ (144 g fenbendazole) premix at Avondale, Blairstown, and Shades, respectively.

For Trials 1 and 2, we collected freshly deposited fecal samples at each area immediately prior to fenbendazole adminsitration and 2 weeks following the final administration of fenbendazole. For Trial 3, we collected abomasa and feces in the distal colon from hunter-harvested deer prior to and following administration of fenbendazole. We attempted to harvest at least 10 deer from each area prior to treatment and all pretreatment deer were harvested within 11 days prior to treatment. Post-treatment deer were collected from each area between 1-3 weeks following final fenbendazole treatment.

Schultz et al. (1993) reported abomasal nematode relative frequencies on these 3 areas and 5 additional areas in south-central Louisiana to be $69.2 \%$ Mazammastrongylus pursglovei, $13.8 \%$ Osteragia mossi, $10.6 \%$ Trichostrongylus askivali, $5.1 \% O$. dikmansi, $0.5 \%$ Haemonchus spp., and $0.4 \%$ M. odocoilei. Abomasa were collected and abomasal parasite counts derived to determine if egg counts were reflecting removal of parasites or inhibition of egg output. Although eggs are produced by gastrointestinal nematodes other than abomasal parasites, previous work on abomasal parasite burdens of deer in Louisiana indicated that abomasal parasite counts and fecal egg counts were associated positively ( $r=$ $0.656, P<0.001$ ) (Schultz et al. 1993).

Each abomasum was recovered and prepared using a standard method (Eve and Kellogg 1977). We randomly selected 2, 50-ml aliquots from each 1,000-ml abomasal sample and washed contents in a $\# 120$ U.S. standard sieve $(0.0049 ")$. Sieve contents were washed into a $1,000-\mathrm{ml}$ beaker, transferred to a flask, and stained with iodine solution. We examined flask contents in a gridded petri dish under a bionocular dissecting microscope (10x) and counted all adult and larval worms observed in each aliquot to derive abomasal parasite count. We processed fecal samples collected during each trial as for captive deer. 


\section{Analytical Methods}

Analyses were performed using log-transformed data to approximate a normal distribution (Eve and Kellogg 1977, Steel and Torrie 1980:235, Couvillion et al. 1982, Schultz et al. 1993). Means, standard errors, and percent reductions were also calculated from the raw data and are presented for comparison to other studies.

We used Student's $t$-tests to evaluate differences between pretreatment versus post-treatment eggs per gram means for captive deer trials separately and to compare eggs per gram means between trials. We used analysis of variance and a block design to determine effects from fenbendazole treatment and study area on eggs per gram and abomasal parasite count values for free-ranging deer. The association between transformed abomasal parasite counts and fecal eggs per gram from individual deer was described using Pearson's correlation coefficient $(r)$. Each trial was analyzed separately and all tests were conducted at $\propto=0.05$.

\section{Results}

\section{Captive Deer}

Although pretreatment and post-treatment fecal eggs per gram means were lower during Trial 2 than during Trial 1 (Table 1),

Table 1. Mean number of gastrointestinal nematode eggs per gram from fecal groups collected from captive white-tailed deer pre- and posttreatment with fenbendazolea during May 1990 (Trial 1) and August 1990 (Trial 2), East Feliciana Parish, La.

\begin{tabular}{|c|c|c|c|c|c|c|c|}
\hline \multirow[b]{2}{*}{ Trial } & \multirow[b]{2}{*}{ Time } & \multirow[b]{2}{*}{$\mathbf{N}$} & \multicolumn{2}{|c|}{$\mathbf{R a w}^{\mathrm{b}}$} & \multicolumn{2}{|c|}{$\log _{10}{ }^{c}$} & \multirow[b]{2}{*}{$\mathrm{P}>(t)^{d}$} \\
\hline & & & $\bar{x}$ & SE & $\bar{x}$ & $\overline{S E}$ & \\
\hline 1 & $\begin{array}{l}\text { Pre } \\
\text { Post }\end{array}$ & $\begin{array}{l}30 \\
31\end{array}$ & $\begin{array}{l}6.1 \\
0.7\end{array}$ & $\begin{array}{l}1.6 \\
0.2\end{array}$ & $\begin{array}{l}0.69 \\
0.17\end{array}$ & $\begin{array}{l}0.06 \\
0.04\end{array}$ & $<0.01$ \\
\hline 2 & $\begin{array}{l}\text { Pre } \\
\text { Post }\end{array}$ & $\begin{array}{l}30 \\
30\end{array}$ & $\begin{array}{l}3.7 \\
0.6\end{array}$ & $\begin{array}{l}0.8 \\
0.5\end{array}$ & $\begin{array}{l}0.53 \\
0.08\end{array}$ & $\begin{array}{l}0.07 \\
0.04\end{array}$ & $<0.01$ \\
\hline
\end{tabular}

Approximately $0.47 \mathrm{~g} /$ deer and $0.62 \mathrm{~g} /$ deer for Trials 1 and 2 , respectively.

Calculated from the raw data.

Calculated from $\log _{10}$-transformed data.

${ }^{d}$ Probability of $>(t)$ of a difference between pre- and post-treatment means using transformed data.

neither pretreatment $(P=0.17)$ nor post-treatment $(P=0.91)$ means differed statistically between trials. Post-treatment eggs per gram means differed from pretreatment means for both trials $(P<0.01)$ and pretreatment means were reduced $89 \%$ and $84 \%$ based upon the raw data following fenbendazole treatment for Trials 1 and 2 , respectively.

\section{Free-Ranging Deer}

Neither fenbendazole treatment $(P=0.61)$, study area $(P=0.44)$, nor the interaction of these variables $(P=0.38)$ affected fecal eggs per gram for Trial 1 (Table 2). Mean pretreatment eggs per gram levels were reduced an average of $86 \%$ (SE $=1.9$ ) among study areas following fenbendazole treatment in Trial 2 based upon the raw data. Fenbendazole treatment $(P=0.04)$ affected eggs per gram values during this trial as did the interaction between fenbendazole treatment and study area $(P=0.01)$; however, study areas did not affect fecal eggs per gram $(P=0.38)$ when tested against the interaction of these variables.

Transformed abomasal parasite counts and fecal eggs per gram from individual deer were positively associated $(r=0.706, P<0.001)$. Pretreatment eggs per gram values and abomasal parasite counts were reduced an average of $66 \%(\mathrm{SE}=5.1)$ and $52 \%(\mathrm{SE}=7.4)$, respectively, following fenbendazole treatment in Trial 3 calculated from the raw means (Table 3$)$. Neither study area $(P=0.24)$ nor the interaction of study area and fenbendazole treatment $(P=$ $0.57)$ affected eggs per gram of feces in Trial 3, but eggs per gram were affected by fenbendazole treatment $(P<0.01)$. Both fenbendazole treatment $(P<0.01)$ and study area $(P=0.04)$ influenced abomasal parasite counts in Trial 3 , but the interaction of these variables did not affect abomasal parasite counts $(P=0.89)$.

\section{Discussion}

Fenbendazole was efficacious for reducing gastrointestinal nematode burdens in captive and free-ranging white-tailed deer as reflected by fecal eggs per gram and abomasal parasite count levels. Although eggs per gram of feces from captive deer were reduced after provision of fenbendazole at average doses of $0.47 \mathrm{~g} /$ deer and $0.62 \mathrm{~g} /$ deer, provision of similar doses to free-ranging deer $(0.42-0.46 \mathrm{~g} /$ deer $)$ did not affect eggs per gram levels. This may have been the result of underestimation of free-ranging deer densities, consumption of fenbendazole-treated corn by species other than deer, or differences in behavior and feeding patterns between captive and free-ranging deer.

Treated feed comprised a major portion of the diet of captive deer and all deer probably consumed treated feed during each trial. Treated corn, however, was a dietary supplement for free-ranging deer. Some free-ranging deer that utilized supplemental corn may not have visited bait stations when treated corn was available during Trial 1, and deer that visited bait stations when treated corn was available may have consumed more than their share (greater than the calculated mean). In Trials 2 and 3, provision of larger doses of fenbendazole ( $1.67-1.82 \mathrm{~g} /$ deer) over a longer period than in Trial 1 reduced fecal eggs per gram and abomasal parasite counts of free-ranging deer. Regardless of the reason that there were no effects from fenbendazole treatment of free-ranging deer during Trial 1 , increasing the dose and period of fenbendazole provision in Trials 2 and 3 resulted in reduced gastrointestinal nematode burdens.

Table 2. Mean number of gastrointestinal nematode eggs per gram in white-tailed deer fecal groups collected on portions of 3 properties pre- and post-treatment with fenbendazole during May 1990 (Trial 1) and July 1990 (Trial 2), East Feliciana Parish, La.

\begin{tabular}{|c|c|c|c|c|c|c|c|c|c|c|c|}
\hline \multirow[b]{3}{*}{ Area $^{a}$} & \multirow[b]{3}{*}{ Time } & \multicolumn{5}{|c|}{$\begin{array}{c}\text { Trial } 1 \\
\text { (estimated } 0.42-0.46 \mathrm{~g} / \text { deer) }\end{array}$} & \multicolumn{5}{|c|}{$\begin{array}{c}\text { Trial } 2 \\
\text { (estimated } 1.67-1.82 \mathrm{~g} / \text { deer) }\end{array}$} \\
\hline & & \multirow[b]{2}{*}{$\mathbf{N}$} & \multicolumn{2}{|c|}{ Raw $^{\mathrm{b}}$} & \multicolumn{2}{|c|}{$\log _{10} c$} & \multirow[b]{2}{*}{$\mathbf{N}$} & \multicolumn{2}{|c|}{ Raw $^{b}$} & \multicolumn{2}{|c|}{$\log _{10} c$} \\
\hline & & & $\bar{x}$ & SE & $\bar{x}$ & SE & & $\vec{x}$ & SE & $\bar{x}$ & $\mathrm{SE}$ \\
\hline Avon & $\begin{array}{l}\text { Pre } \\
\text { Post }\end{array}$ & $\begin{array}{l}19 \\
18\end{array}$ & $\begin{array}{l}3.4 \\
6.2\end{array}$ & $\begin{array}{l}0.9 \\
3.8\end{array}$ & $\begin{array}{l}0.49 \\
0.43\end{array}$ & $\begin{array}{l}0.09 \\
0.12\end{array}$ & $\begin{array}{l}30 \\
32\end{array}$ & $\begin{array}{l}6.5 \\
1.1\end{array}$ & $\begin{array}{l}1.9 \\
0.5\end{array}$ & $\begin{array}{l}0.55 \\
0.19\end{array}$ & $\begin{array}{l}0.09 \\
0.05\end{array}$ \\
\hline Btown & $\begin{array}{l}\text { Pre } \\
\text { Post }\end{array}$ & $\begin{array}{l}42 \\
42\end{array}$ & $\begin{array}{l}2.8 \\
2.9\end{array}$ & $\begin{array}{l}0.5 \\
0.8\end{array}$ & $\begin{array}{l}0.46 \\
0.35\end{array}$ & $\begin{array}{l}0.05 \\
0.06\end{array}$ & $\begin{array}{l}32 \\
25\end{array}$ & $\begin{array}{l}9.9 \\
0.7\end{array}$ & $\begin{array}{l}1.8 \\
0.3\end{array}$ & $\begin{array}{l}0.83 \\
0.13\end{array}$ & $\begin{array}{l}0.08 \\
0.05\end{array}$ \\
\hline Shades & $\begin{array}{l}\text { Pre } \\
\text { Post }\end{array}$ & $\begin{array}{l}27 \\
27\end{array}$ & $\begin{array}{l}2.6 \\
7.1\end{array}$ & $\begin{array}{l}0.5 \\
2.8\end{array}$ & $\begin{array}{l}0.45 \\
0.54\end{array}$ & $\begin{array}{l}0.06 \\
0.10\end{array}$ & $\begin{array}{l}30 \\
32\end{array}$ & $\begin{array}{r}15.6 \\
2.7\end{array}$ & $\begin{array}{l}3.0 \\
1.1\end{array}$ & $\begin{array}{l}1.04 \\
0.26\end{array}$ & $\begin{array}{l}0.08 \\
0.08 \\
\end{array}$ \\
\hline
\end{tabular}

Avon = Avondale Hunting Camp, Btown = Blairstown Plantation, Shades = Shades Plantation.

b Calculated from the raw data.

${ }^{\circ}$ Calculated from $\log _{10}$-transformed data. 
Table 3. Mean number of gastrointestinal nematode eggs per gram in white-tailed deer feces collected from the distal colon and abomasal parasite counts (APC) from abomasa collected from deer harvested from 3 properties pre- and post-treatment with fenbendazole ${ }^{\mathrm{a}}$ during November 1990 , East Feliciana Parish, La.

\begin{tabular}{|c|c|c|c|c|c|c|c|c|c|c|c|}
\hline \multirow[b]{3}{*}{ Area } & \multirow[b]{3}{*}{ Time } & \multicolumn{5}{|c|}{ EPG } & \multicolumn{5}{|c|}{$\mathrm{APC}$} \\
\hline & & \multirow[b]{2}{*}{$\mathbf{N}$} & \multicolumn{2}{|c|}{$\operatorname{Raw}^{\mathrm{b}}$} & \multicolumn{2}{|c|}{$\log _{10} c$} & \multirow[b]{2}{*}{$\mathbf{N}$} & \multicolumn{2}{|c|}{$\mathrm{Raw}^{\mathrm{b}}$} & \multicolumn{2}{|c|}{$\log _{10} c$} \\
\hline & & & $x$ & SE & $\bar{x}$ & $\mathrm{SE}$ & & $\bar{x}$ & $\mathrm{SE}$ & $\bar{x}$ & SE \\
\hline$\overline{\text { Avon }}$ & $\begin{array}{l}\text { Pre } \\
\text { Post }\end{array}$ & $\begin{array}{l}13 \\
11\end{array}$ & $\begin{array}{r}20.9 \\
8.2\end{array}$ & $\begin{array}{l}5.1 \\
3.3\end{array}$ & $\begin{array}{l}1.12 \\
0.58\end{array}$ & $\begin{array}{l}0.15 \\
0.20\end{array}$ & $\begin{array}{l}13 \\
11\end{array}$ & $\begin{array}{r}1,536 \\
803\end{array}$ & $\begin{array}{l}262 \\
394\end{array}$ & $\begin{array}{l}3.10 \\
1.93\end{array}$ & $\begin{array}{l}0.08 \\
0.39\end{array}$ \\
\hline Btown & $\begin{array}{l}\text { Pre } \\
\text { Post }\end{array}$ & $\begin{array}{l}21 \\
16\end{array}$ & $\begin{array}{r}33.9 \\
5.5\end{array}$ & $\begin{array}{r}17.4 \\
2.3\end{array}$ & $\begin{array}{l}1.02 \\
0.43\end{array}$ & $\begin{array}{l}0.14 \\
0.14\end{array}$ & $\begin{array}{l}21 \\
16\end{array}$ & $\begin{array}{l}596 \\
401\end{array}$ & $\begin{array}{r}76 \\
211\end{array}$ & $\begin{array}{l}2.64 \\
1.27\end{array}$ & $\begin{array}{l}0.10 \\
0.33\end{array}$ \\
\hline Shades & $\begin{array}{l}\text { Pre } \\
\text { Post }\end{array}$ & $\begin{array}{r}9 \\
10\end{array}$ & $\begin{array}{l}6.4 \\
2.9\end{array}$ & $\begin{array}{l}2.2 \\
1.1\end{array}$ & $\begin{array}{l}0.68 \\
0.42\end{array}$ & $\begin{array}{l}0.15 \\
0.13\end{array}$ & $\begin{array}{r}9 \\
12\end{array}$ & $\begin{array}{r}1,467 \\
347 \\
\end{array}$ & $\begin{array}{l}548 \\
137 \\
\end{array}$ & $\begin{array}{l}3.02 \\
1.84\end{array}$ & $\begin{array}{l}0.11 \\
0.31\end{array}$ \\
\hline
\end{tabular}

${ }^{a}$ Estimated $1.67-1.82 \mathrm{~g} /$ deer

b Avon = Avondale Hunting Camp, Btown = Blairstown Plantation, Shades $=$ Shades Plantation

Avon = Avondale Hunting Cam
${ }^{b}$ Calculated from the raw data.

Calculated from $\log _{10}$-transformed data.

Although fenbendazole treatment reduced eggs per gram of feces from captive deer during Trial 1 'nd free-ranging deer during Trial 2, eggs per gram values were again tlevated when subsequent trials began. Previous contamination of pastures apparently provided an adequate reservoir of gastrointestinal nematodes to permit relatively rapid reinfection. Janssen (1985) suggested that effects of anthelmintic treatment will be short-lived unless pasture contamination is reduced and Myers (1988) recommended pasture rotation to reduce contamination. Pasture rotation might be possible with captive deer but obviously could not be utilized for free-ranging deer. Repeated fenbendazole treatments would be required for long-term reductions in gastrointestinal nematode burdens.

A relatively minor proportion of the gastrointestinal nematode parasites identified by Schultz et al. (1993) from deer on these and other properties in the region are common in livestock. However, our results suggest that efficacious treatment could be expected in cases where species common to deer and livestock comprise a greater proportion of the deer gastrointestinal nematode burden.

\section{Conclusions}

Our results indicate that white-tailed deer gastrointestinal nematode burdens can be reduced through administration of fenbendazole. These results have direct implications toward captive deer

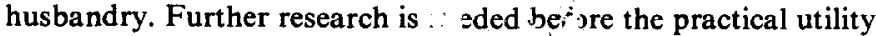
of fenbendazole treatment agains ${ }^{\dagger}$ grsic itestinal nematodes in free-ranging deer can be adequate $;$.c. Iressed. Provision of fenbendazole for treatment of high gastrointest 1 al nematode burdens in free-ranging deer would probably $p$ sitively affect deer populations. However, decreases in numbers f these parasites in cases where burdens are moderate or low might result in little actual benefit to deer. The interrelationship and crosstransmission of gastrointestinal nematode parasites between domestic livestock and free-ranging deer must be further delineated before effects can be described for livestock grazing the same range as free-ranging deer treated to reduce gastrointestinal nematode burdens. Our results suggest that crosstransmission of gastrointestinal nematode parasites from deer to livestock might be reduced through fenbendazole treatment of deer and they provide the foundation for continued research regarding treatment of these parasites in deer and effects of such treatment on other ruminants utilizing the same range.

\section{Literature Cited}

Anderson, M.V., and P.R. Wilson. 1984. Deer parasite studies. Proc. Deer Course for Vet. 1:78-88.
Anderson, R.C. 1962. The parasites (helminths and arthropods) of whitetailed deer. Proc. First Nat. White-tailed Deer Dis. Symp. 1:162-173.

Barry, R.X. 1991. Effects of food plots on gastrointestinal nematode burdens of white-tailed deer. M.S. Thesis, Louisiana State Univ., Baton, Rouge.

Beaudion, R.L., W.M. Samuel, and C.P.A. Strome. 1970. A comparative study of the parasites in two populations of white-tailed deer. J. Wildl. Dis. 6:56-63.

Bockeler, W., and K.H. Lindau. 1978. Experience with Panacur ${ }^{R}$ in mammals at the Cologne Zoo. Z. Koeln. Zoo. 20:115-118.

Boyce, W., J. Allen, C. Himmelwright, L. Elliott, A. Mikolon, J. Mazet, and I. Gardner. 1991. Implementation and evaluation of a strategic parasite control program from captive exotic ungulates. J. Amer. Vet Med. Assoc. 198:1972-1976.

Conti, J.A., and E.W. Howerth. 1987. Osteragiosis in a white-tailed deer due to Ostertagia ostertagia. J. Wildl. Dis. 23:159-162.

Couvillion, C.E., C.B. Crow, and W.R. Davidson. 1982. An evaluation of hunter-killed white-tailed deer for abomasal parasite count (APC) studies. Proc. Southeast. Assoc. Fish and Wildl. Agencies 36:427-435.

Davidson, W.R., M.B. McGhee, V.F. Nettles, and L.C. Chappell. 1980. Haemonchosis in white-tailed deer in the southeastern United States. J. Wildl. Dis. 16:499-508.

Davidson, W.R., J.S. Osborne, and F.A. Hayes. 1982. Abomasal parasitism and physical condition in southeastern white-tailed deer. Proc. Annu. Conf. Southeast. Assoc. Fish and Wildl. Agencies 36:436-444.

Delany, B.W. 1985. Effects of cool-season food plots on white-tailed deer M.S. Thesis, Louisiana State Univ., Baton Rouge, La.

Dinnes, M.R., and P.J. Knapman. 1980. Preliminary studies on the use of fenbendazole in non-domestic animals. Proc. Amer. Assoc. Zoo. Vet. $162-163$.

Dunn, A.M. 1968. The wild ruminant as reservoir host of helminth infection. Symp. Zoo. Soc. London 24:221-248.

Duwel, D., R. Kirsch, and B. Tiefenbach. 1979. On the treatment of the nematode infection of game with Panacur ${ }^{\mathrm{R}}$. Berl. Munch. Tier. Wochen. 92:400-405.

English, A.W. 1985. Diseases of fallow deer in New South Wales, Australia. p. 93-96. In: P.F. Fennessy and K.R. Drew (eds.), Biology of deer production. The Royal Soc. of N.Z., Wellington.

Eve, J.H., and F.E. Kellogg. 1977. Management implications of abomasal parasites in southeastern white-tailed deer. J. Wildl. Manage. 41:169-177.

Foreyt, W.J., and W.M. Samuel. 1979. Parasites of white-tailed deer of the Welder Wildlife Refuge in southern Texas: A review. Proc. First Welder Wildl Found. Symp. 1:105-132.

Forrester, D.J., W.J. Taylor, and K.P.C. Nair. 1974. Stronglyoides in captive white-tailed deer. J. Wildl. Dis. 10:11-17.

Fraser, C.M., Ed. 1986. The Merck veterinary manual, sixth edition. Merck and Co., Inc., Rahway, N.J.

Garris, G.I., J.B. Prullage, J.L. Prullage, F.C. Wright, and J.A. Miller. 1991. Control of Psoroptes cuniculi in captive white-tailed deer with ivermectin-treated corn. J. Wildl. Dis. 27:254-257.

Hayne, D.W. 1949. An examination of the strip census method for estimating animal populations. J. Wildl. Manage. 13:145-157.

Herman, C.B. 1945. Deer management problems as related to diseases and parasites of domestic range livestock. Trans. North Amer. Wildl. Conf. $10: 242-246$. 
Janssen, D.L. 1985. Efficacy of fenbendazole for endoparasite control in large herds of nondomestic ruminants. J. Amer. Vet. Med. Assoc. 187:1189-1190.

Kutzer, E. 1981. The use of fenbendazole $\left(\right.$ Panacur $\left.^{R}\right)$ in game preserves Proc. Int. Symp. Dis. Zoo Anim. 23:243-245.

Mason, P.C., and N.R. Gladden. 1983. Survey of intrnal parasitism and anthelmintic use in farmed deer. N.Z. Vet. J. 31:217-220.

McGhee, M.B., V.F. Nettles, E.A. Rollor, III, A.K. Prestwood, and W.R. Davidson. 1981. Studies on cross-transmission and pathogenicity of Haemonchus contortus in white-tailed deer, domestic cattle and sheep. J. Wildl. Dis. 17:353-364.

Myers, G.H. 1988. Strategies to control internal parasites in cattle and swine. J. Anim. Sci. 66:1555-1564.

Prestwood, A.K., F.A. Hayes, L.H. Eve, and J.F. Smith. 1973. Abomasal helminths of white-tailed deer in the southeastern United States, Texas, and the Virgin Islands. J. Amer. Vet. Med. Assoc. 163:556-561.

Prestwood, A.K., and F.E. Kellogg. 1971. Naturally occurring haemonchosis in a white-tailed deer. J. Wildl. Dis. 7:133-134.

Prestwood, A.K., F.E. Kellogg, S.R. Pursglove, and F.A. Hayes. 1975. Helminth parasitisms among intermingling insular populations of whitetailed deer, feral cattle, and feral swine. J. Amer. Vet. Med. Assoc. 166:787-789.

Prestwood, A.K., and S.R. Pursglove. 1981. Gastrointestinal nematodes, p. 318-350. In: W.R. Davidson, F.A. Hayes, V.F. Nettles, and F.E. Kellogg (eds.), Diseases and parasites of white-tailed deer. Tall Timbers Res. Sta. Misc. Pub. 7, Tallahassee, Fla.
Prestwood, A.K., S.R. Pursglove, and F.A. Hayes. 1976. Parasitism among white-tailed deer and domestic sheep on common range. J. Wildl. Dis. 12:380-385.

Qureshi, T., T.M. Craig, D.L. Drawe, and D.S. Davis. 1989. Efficacy of triclabendazole against fascioloidiasis (Fascioloides magna) in naturally infected white-tailed deer (Odocoileus virginianus). J. Wildl. Dis. 25:378-383.

Qureshi, T., D.S. Davis, and D.L. Drawe. 1990. Use of albendazole in feed to control Fasciolodes magna infections in captive white-tailed deer (Odocoileus virginianus). J. Wildl. Dis. 26:231-235.

Samuel, W.M., and D.O. Trainer. 1969. A technique for survey of some helminth and protozoan infections of white-tailed deer. J. Wildl. Manage. 33:888-894.

Schultz, S.R., M.K. Johnson, R.X. Barry, and W.A. Forbes. 1993. Whitetailed deer abomasal parasite counts and fecal egg counts in Louisiana. Wildl. Soc. Bull. In Press.

Steel, R.G.D., and J.H. Torrie. 1980. Principles and procedures of statistics. McGraw-Hill Book Co., N.Y.

Watson, T.G., and W.A.G. Charleston. 1985. The significance of parasites in farmed deer. p. 105-117. In: P.F. Fennessy and K.R. Drew (eds.), Biology of deer production. The Royal Soc. of N.Z., Wellington.

Wiegand, D. 1981. Chemotherapy of endoparasitic infections in a deer population with Panacur ${ }^{R}$. Deut. Tier. Wochen. 88:192-195.

Wilson, P.R. 1984. Diseases of farmed deer. Proc. Univ. of Sydney PostGraduate Committee in Vet. Sci. Refresher Course for Vets. 72:505-530. 